\title{
EVALUASI KESESUAIAN LAHAN KUALITATIF DAN KUANTITATIF PERTANAMAN UBI KAYU (Manihot esculenta Crantz) DI LAHAN KELOMPOK TANI USAHA MAJU DESA TANJUNG SENANG KECAMATAN KOTABUMI SELATAN LAMPUNG UTARA
}

\author{
Imam Ash Shiddiq, Ali Kabul Mahi, Kuswanta F Hidayat \& Afandi \\ Jurusan Agroteknologi, Fakultas Pertanian Universitas Lampung \\ Jl. Prof. Dr. Soemantri Brodjonegoro no. 1 Bandar Lampung 35145 \\ Email:imamash_shiddiq@yahoo.com
}

\begin{abstract}
ABSTRAK
Tanaman ubi kayu (Manihot esculenta Crantz) adalah tanaman pangan ketiga setelah padi dan jagung. Selain sebagai pengganti beras, ubi kayu juga banyak dibutuhkan oleh pabrik pembuat tepung tapioka.Tanaman ubi kayu sebagian besar dikembangkan secara vegetatif yakni dengan stek. Jenis bahan tanaman (klon) ubi kayu yang banyak ditanam di Lampung antara lain adalah klon UJ-3 (Thailand), klon UJ-5 (Cassetsart), dan klon lokal. Dalam penelitian ini mengunakan klon UJ-5. Evaluasi kesesuaian lahan dilakukan secara kualitatif, dengan mengunakan metode survei evaluasi lahan secara pararel sedangkan penilaian secara ekonomi adalah dengan menganalisa kelayakan finansial budidaya tanaman ubi kayu yang dilakukan dengan menghitung nilai NPV, Net B/C Ratio, dan IRR. Hasil penelitian lahan pertanaman ubi kayu (Manihot esculenta Crantz) di lahan Kelompok Tani Usaha Maju Desa Tanjung Senang Kecamatan Kotabumi Selatan Lampung Utara termasuk ke dalam kelas kesesuaian lahan cukup sesuai dengan faktor pembatas retensi hara berupa KTK dan pH tanah (S2nr). Akan tetapi secara finansial, usaha budidaya tanaman ubi kayu dalam 3 musim menguntungkan dan layak untuk dikembangkan. Hal ini dibuktikan dari hasil NPV rata - rata yang diperoleh petani sebesar Rp51.754.497, Net B/C rata - rata sebesar 2,618, IRR rata - rata sebesar $11 \%$ bulan $^{-1}$.
\end{abstract}

Kata kunci : Kesesuaian lahan kualitatif, kelayakan finansial ubi kayu klon UJ-5.

\section{PENDAHULUAN}

Ubi kayu peranannya dalam perekonomian nasional terus meningkat karena dianggap sebagai komoditas yang memiliki potensi untuk dikembangkan dan dapat dimanfaatkan oleh berbagai industri. Macammacam bentuk olahan ubi kayu yang memiliki nilai jual tinggi antara lain; mocaf (modified cassava flour) yang memerlukan ubi kayu 1-juta ton tahun ${ }^{-1}$, untuk industri keripik singkong yang memerlukan ubi kayu 21 ton hari 1, dan untuk menghasilkan 1 liter bioetanol maka membutuhkan ubi kayu segar sebanyak $6 \mathrm{~kg}$ untuk memenuhi kebutuhan bensin tanah air yang telah mencapai 126,04 juta liter tahun ${ }^{-1}$. Seandainya $5 \%$ saja digantikan bioetanol maka kebutuhan ubi kayu segar dapat mencapai 38 juta ton (Arifin dkk., 2012).

\section{BAHAN DAN METODE}

Penelitian dilakukan di lahan ubi kayu milik Kelompok Tani Usaha Maju Desa Tanjung Senang dengan luas 10 ha yang terletak pada wilayah Kecamatan Kotabumi Selatan, Kabupaten Lampung
Utara. Lokasi penelitian berada pada koordinat 04'52.938'-04'53.017' mT dan 104'53.219'04053.462' mU. Penelitian dilakukan pada bulan Desember 2012 sampai dengan Januari 2013 dan analisis tanah dilakukan di Laboratorium Ilmu Tanah Fakultas Pertanian Universitas Lampung.

Alat-alat yang digunakan antara lain meteran, global positioning system (GPS), munsell Soil Color Chart, bor tanah, kantung plastik, kamera digital, alatalat tulis, dan alat-alat laboratorium. Bahan-bahan yang digunakan antara lain contoh tanah dan bahan-bahan kimia untuk analisis tanah di laboratorium.

Penelitian dilakukan dengan menggunakan metode survei evaluasi lahan secara paralel, yaitu melakukan evaluasi lahan kualitatif (biofisik) dan kuantitatif (finansial) secara bersamaan.Evaluasi lahan kualitatif dilakukan berdasarkan kriteria biofisik. Djaenuddin dkk. (2000), sedangkan evaluasi lahan kuantitatif dilakukan dengan menghitung nilai kelayakan finansial dengan menghitung NPV, Net B/C Ratio, dan IRR (Ibrahim, 2003).

Data yang dikumpulkan meliputi data fisik dan data sosial ekonomi. Data fisik antara lain data fisik 
primer yaitu data yang diamati dan diukur langsung di lapang (drainase, bahan kasar, kedalam tanah, lereng, bahaya erosi, genangan, batuan dipermukaan dan batuan singkapan) dan data yang dianalisis di laboratorium (KTK tanah, basa-basa yang dapat dipertukarkan, $\mathrm{pH}$ tanah, C-organik dan tekstur tanah), sedangkan data fisik sekunder berupa suhu dan kelembaban udara diambil 10 tahun terakhir dari stasiun klimatologi setempat. Data sosial ekonomi meliputi data sosial ekonomi primer biaya produksi (bibit, pupuk, pestisida), peralatan, tenaga kerja (pengolahan tanah, penanaman, pemupukan, penyiangan, panen, dll), dan pendapatan selama 3 musim tanam yang diperoleh petani pada lahan penelitian, sedangkan data sosial ekonomi sekunder berupa data luas panen dan hasil produksi ubi kayu.

\section{HASIL DAN PEMBAHASAN}

Analisis kualitatif. Berdasarkan hasil pengumpulan data, baik data primer maupun data sekunder, maka didapatkan rata-rata suhu tahunan di daerah penelitian sebesar $26,7^{\circ} \mathrm{C}$ dan rata-rata kelembaban udara tahunan sebesar $81 \%$. Hasil pengamatan profil tanah di lapang menunjukkan bahwa drainase pada lahan penelitian dikategorikan baik, tekstur tanah agak halus, dan bahan kasar tidak ditemukan $(0 \%)$. Kemudian dari hasil analisis laboratorium didapat bahwa KTK liat sebesar $5,95 \mathrm{Cmol} \mathrm{kg}^{-1}$, Kejenuhan basa sebesar 43,53\%, pH $\mathrm{H}_{2} \mathrm{O}$ sebesar 4,96, dan C-organik sebesar 1,48 \%.Hasil analisis data didapat bahwa kelas kesesuaian lahan kualitatif untuk tanaman ubi kayu pada lahan penelitian termasuk kedalam kategori kelas kesesuaian lahan cukup sesuai dengan faktor pembatas berupa KTK liat dan $\mathrm{pH}$ tanah (S2nr), seperti yang tertera pada Tabel 1 .

Analisis kuantitatif. Biaya usaha tani tanaman ubi kayu pada lahan penelitian terdiri dari biaya tetap dan biaya variabel. Biaya tetap pada lahan penelitian terdiri dari biaya sewa lahan sebesar Rp 3.000.000,-, dan peralatan pertanian sebesar Rp 330.000,-.Sedangkan, biaya variabel terdiri dari biaya bibit sebesar Rp 1.000.000,-, pupuk kimia sebesar Rp 615.000,-, pupuk kandang sebesar Rp 500.000,-, herbisida sebesar Rp $65.000,-$, dan biaya tenaga kerja borongan sebesar $\mathrm{Rp}$ $1.650 .000,-$.

Penerimaan dari penjualan ubi kayu pada tiap musim tanam selalu mengalami perubahan.Pada musim tanam pertama dan kedua diperoleh penerimaan bersih rata-rata sebesar $\mathrm{Rp} 18.400 .000$,- dan $\mathrm{Rp} 18.480 .000$,kemudian pada musim tanam ketiga diperoleh penerimaan rata-rata sebesar Rp20.510.000,-, Total penerimaan rata-rata usahatani ubi kayu selama tiga musim tanam adalah sebesar Rp 19.130.000,-. Analisis finansial dilakukan dengan menghitung nilai penerimaan bersih sekarang, nilai perbandingan antara penerimaan bersih dan biaya serta nilai tingkat pengembalian internal dengan menggunakan tingkat suku bunga yang berlaku dimasyarakat saat ini.

Tingkat suku bunga yang berlaku diasumsikan sebesar $15 \%$. Berdasarkan hasil perhitungan data maka diperoleh rata-rata NPVsebesar Rp 51.754.497, Net B/ C sebesar 2,618 dan IRRsebesar $11 \%$ tahun $^{-1}$. Berdasarkan hasil perhitungan nilai NPV,nilai Net B/ Cratio lebih besar dari 1 dan nilai IRRlebih besar dari suku bunga yang diasumsikan, maka hasil tersebutmenunjukkan bahwa usaha budidaya tanaman ubi kayu selama periode tiga musim tanam (2010 -2012) menguntungkan dan layak untuk dilanjutkan.

Berdasarkan hasil penelitian yang telah dilakukan pada lahan pertanaman ubi kayu baik secara langsung di lapang maupun analisis di laboratorium.Maka, didapat dua faktor pembatas berupa KTK liat dan $\mathrm{pH}$ tanah yang masuk kedalam kategori kelas kesesuaian lahan cukup sesuai (S2nr).

Berdasarkan hasil analisis contoh tanah di laboraturium adalah, tanah bertekstur agak halus, hal ini ditunjukan dengan persentase kandungan pasir $38,53 \%$, debu $25,84 \%$, dan liat $35,63 \%$, sehingga menurut kriteria Djaenuddin dkk. (2000), termasuk ke dalam kelas kesesuaian lahan sangat sesuai (S1). Tanah yang paling sesuai untuk tanaman ubi kayu adalah tanah yang berstruktur remah, gembur dan memiliki tekstur berpasir hingga liat, akan tetapi dapat tumbuh dengan baik pada tanah lempung berpasir yang cukup hara (FAO, 1976). Tanah dengan struktur yang remah memiliki tata udara yang baik, unsur hara lebih mudah tersedia dan mudah diserap oleh tanaman. Untuk pertumbuhan tanaman ubi kayu yang optimal, maka tanah harus subur dan kaya akan bahan organik baik dari unsur makro maupun mikronya (Huda, 2010).

Keasaman tanah merupakan hal yang sangat penting karena akan berkaitan dengan pertimbangan dalam pemberian pupuk, pengapuran dan perbaikan keadaan kimia dan fisik tanah. Tanaman ubi kayu masih mampu memberikan hasil pada kondisi tanah yang masam ( $\mathrm{pH}$ rendah) dengan tingkat kesuburan yang rendah (Cock, 1983).

Kelas kesesuaian lahan kualitatif. Berdasarkan hasil analisis laboratorium nilai $\mathrm{pH}$ tanah pada lahan penelitian sebesar 4,96, sehingga berdasrkan kriteria Djaenuddin dkk.(2000) termasuk kelas kesesuaian lahan S2. Dengan hasil perhitungan ini diketahui bahwa untuk menaikan pH dari 4,95 menjadi 6,1 maka dibutuhkan penambahan kapur pertanian sebanyak 1,15 ton $\mathrm{ha}^{-1}$. Kapasitas tukar kation (KTK) merupakan sifat kimia 
Tabel 1. Kelas Kesesuaian Lahan Tanaman Ubi Kayu Daerah Penelitian.

\begin{tabular}{|c|c|c|c|c|}
\hline \multirow{3}{*}{$\begin{array}{l}\text { No. } \\
1\end{array}$} & \multirow{2}{*}{$\begin{array}{l}\text { Kualitas / Karakteristik Lahan } \\
\text { Temperatur (tc) }\end{array}$} & \multirow[t]{2}{*}{ Nilai } & \multicolumn{2}{|c|}{$\begin{array}{c}\text { Komposit } \\
\text { Kelas Kesesuaian Lahan }\end{array}$} \\
\hline & & & & $\mathrm{S} 1$ \\
\hline & Suhu tahunan rata-rata $\left({ }^{0} \mathrm{C}\right)$ & 26,7 & $\mathrm{~S} 1$ & \\
\hline \multirow[t]{2}{*}{2} & Ketersediaan air (wa) & & & $\mathrm{S} 1$ \\
\hline & Curah hujan (mm) tahunan & $1.929,78$ & $\mathrm{~S} 1$ & \\
\hline \multirow[t]{2}{*}{3} & Ketersediaan oksigen (oa) & & & $\mathrm{S} 1$ \\
\hline & Drainase & Baik & $\mathrm{S} 1$ & \\
\hline \multirow[t]{4}{*}{4} & Media perakaran (rc) & & & $\mathrm{S} 1$ \\
\hline & Tekstur tanah & Agak Halus & $\mathrm{S} 1$ & \\
\hline & Bahan kasar (\%) & 0 & $\mathrm{~S} 1$ & \\
\hline & Kedalaman tanah (cm) & $>120 \mathrm{~cm}$ & $\mathrm{~S} 1$ & \\
\hline \multirow[t]{5}{*}{5} & Retensi hara (nr) & & & $\mathrm{S} 2$ \\
\hline & KTK liat $\left(\mathrm{cmol} \mathrm{kg}^{-1}\right)$ & 5,95 & $\mathrm{~S} 2$ & \\
\hline & Kejenuhan basa (\%) & 43,53 & $\mathrm{~S} 1$ & \\
\hline & $\mathrm{pH}$ tanah $(\mathrm{H} 2 \mathrm{O})$ & 4,96 & $\mathrm{~S} 2$ & \\
\hline & C-Organik (\%) & 1,48 & $\mathrm{~S} 1$ & \\
\hline \multirow[t]{2}{*}{6} & Toksisitas (xe) & & & $\mathrm{S} 1$ \\
\hline & Salinitas $\left(\mathrm{ds} \mathrm{m}^{-1}\right)$ & $<2$ & S1 & \\
\hline \multirow[t]{2}{*}{7} & Bahaya sulfidik (xs) & & & $\mathrm{S} 1$ \\
\hline & Kedalaman sulfidik $(\mathrm{cm})$ & $>100 \mathrm{~cm}$ & $\mathrm{~S} 1$ & \\
\hline \multirow[t]{3}{*}{8} & Bahaya erosi (eh) & & & $\mathrm{S} 1$ \\
\hline & Lereng $(\%)$ & $3 \%$ & S1 & \\
\hline & Bahaya erosi & $\mathrm{Sr}$ & $\mathrm{S} 1$ & \\
\hline \multirow[t]{2}{*}{9} & Bahaya banjir (fh) & & & $\mathrm{S} 1$ \\
\hline & Genangan & $\mathrm{F} 0$ & $\mathrm{~S} 1$ & \\
\hline \multirow[t]{5}{*}{10} & Penyiapan lahan (lp) & & & $\mathrm{S} 1$ \\
\hline & Batuan permukaan (\%) & 0 & $\mathrm{~S} 1$ & \\
\hline & Singkapan batuan (\%) & 0 & $\mathrm{~S} 1$ & \\
\hline & KELAS KESESUAIAN LAHAN & & & $\mathrm{S} 2$ \\
\hline & SUB KELAS KESESUAIAN LAHAN & & & S2nr \\
\hline
\end{tabular}

Keterangan : $\mathrm{F} 0=$ tidak pernah tertutup banjir selama 24 jam dalam satu tahun.

yang sangat erat hubungannya dengan kesuburan tanah. Tanah-tanah dengan kandungan bahan organik atau kadar liat tinggi mempunyai KTK lebih tinggi daripada tanah-tanah dengan kandungan bahan organik rendah atau tanah-tanah berpasir (Hardjowogeno dan
Widiatmaka, 2007). Nilai KTK tanah sangat beragam dan tergantung pada sifat dan ciri tanah itu sendiri. Besar kecilnya KTK tanah dipengaruhi oleh : reaksi tanah, tekstur atau jumlah liat, jenis mineral liat, bahan organik, pengapuran dan pemupukan. Kapasitas tukar kation 
tanah sangat beragam, karena jumlah humus dan liat serta macam liat yang dijumpai dalam tanah berbedabeda pula. Pengaruh kejenuhan basa dan $\mathrm{pH}$ tanah terhadap KTK tanah, KTK tinggi bila didomonasi dengan kation basa $\mathrm{Ca}, \mathrm{Mg}, \mathrm{K}, \mathrm{Na}$, (Kejenuhan basa tinggi dapat meningkatkan kesuburan tanah, tetapi bila di dominasi dengan kation asam $\mathrm{Al}, \mathrm{H}$ (kejenuhan basa rendah) dapat mengurangi kesuburan tanah karena unsur-unsur hara terdapat dalam kompleks jerapan koloid maka unsur-unsur hara tersebut tidak mudah hilang tercuci oleh air (Balai Penelitian Tanah, 2005).

Kesesuaian lahan kuantitatif. Rata - rata produksi ubi kayu yang diperoleh selama 3 musim tanam pada lahan adalah sebesar 28,6 ton ha ${ }^{-1}$. Harga jual ubi kayu selama 3 musim Rp800,- $\mathrm{kg}^{-1}, \mathrm{Rp} 820,-\mathrm{kg}^{-1}, \mathrm{Rp} 850,-\mathrm{kg}^{-1}$

. Rata - rata penerimaan masing-masing petani dari penjualan ubi kayu selama 3 musim tanam pada lahan terdapat perbedaan, hal ini dikarenakan produksi yang diperoleh dan harga jual ubi kayu yang berubah setiap tahun.

Untuk mengetahui tingkat kelayakan usahatani ubi kayu digunakan analisis NPV, Net B/C,danIRR. NPV (nilai pendapatan bersih sekarang) merupakan selisih nilai sekarang pendapatan dengan nilai sekarang investasi selama umur ekonomis tanaman ubi kayu. Tingkat suku bunga yang digunakan adalah $15 \%$ yang merupakan suku bunga yang berlaku di masyarakat saat ini. Dari hasil pengolahan data, pada lahan nilai NPV rata - rata petani sebesar Rp51.754.497,- yang berarti bahwa selama umur 3 tahun usaha tani tanaman ubi kayu akan memberikan nilai pendapatan bersih sebesar Rp51.754.497,-. Berdasarkan besarnya nilai NPV yang diperoleh, dengan demikian dapat dikatakan bahwa usahatani ubi kayu tersebut menguntungkan dan layakuntuk diusahakan.

Net B/C ratio (rasio biaya manfaat bersih) adalah perbandingan antara nilai manfaat bersih dengan biaya bersih yang diperhitungkan nilainya saat ini. Discount dan compounding faktor menggunakan internal rate $15 \%$. Pada lahan tanaman ubi kayu Net B/C rata rata pada lahan ubi kayu sebesar 2,618.Berarti setiap Rp 1,00 yang diinvestasikan selama 3 tahun akan memberikan pengembalian sebesar 2,618 musim $^{-1}$ dandapat dikatakan usahatani ubi kayuini layak atau menguntungkan.

IRR atau tingkat investasi adalah suatu tingkat bunga dimana nilai sekarang pendapatan sama dengan nilai sekarang investasi. Tingkat suku bunga yang berlaku diasumsikan sebesar $15 \%$ setahun dan suku bunga perbulannya sebesar $1,25 \%$. Nilai suku bunga ini digunakan sebagai compounding factor (CF), hal ini disebabkan karena perhitungan finansial dilakukan pada data yang lalu (2010-2012). Dari hasil pengolahan data pada lahan ubi kayunilai IRRrata - ratapetanisebesar $11 \%$ bulan $^{-1}$.

Berdasarkan nilai IRR yang telah diperoleh antara petanipada lahan ubikayu, meskipun kesesuaian lahan kualitatif termasuk ke dalam kelas kesesuaian lahan S2nr, akan tetapi dari segi kelayakan finansial usaha tani ubi kayu di lokasi penelitian menguntungkan dan layak untuk diteruskan.

\section{KESIMPULAN}

Dari hasil pengamatan di lapangan dan pengolahan data primer, maka dapat disimpulkan bahwa lahan pertanaman ubi kayu (Manihot esculenta Crantz) di Lahan Kelompok Tani Usaha Maju Desa Tanjung senang, Kecamatan Kotabumi Selatan, Lampung Utara, termasuk ke dalam kelas kesesuaian lahan cukup sesuai (S2nr) dengan faktor pembatas retensi hara (KTK liat dan $\mathrm{pH}$ ). Secara finansial, usahatani tanaman ubi kayu di Lahan Kelompok Tani Usaha Maju Desa Tanjung Senang, Kecamatan Kotabumi selatan, Lampung Utara menguntungkan dan layak untuk dikembangkan.Hal ini dibuktikan dari hasil NPV rata - rata yang diperoleh petani sebesar Rp 51.754.497, selama 3 musim tanam, Net $\mathrm{B} / \mathrm{C}$ rata - rata sebesar 2,618 , IRR rata - rata sebesar $11 \%$ bulan $^{-1}$.

\section{DAFTAR PUSTAKA}

Arifin, Idawati, dan Suryaatmaja. 2012. Janji Singkong. Majalah Trubus No. 509. Hal 26-31

Balai Penelitian Tanah. 2005. Pupuk organik Tingkatkan Produksi Pertanian. Warta Penelitian dan Pengembangan Pertanian. 27 (6) : 13-15.

Cock, H. J. 1983. Cassava. Potential Productivity of Field Crops Under Different Environment IRRI. Los Banos Philippines p. 85 - 87.

Djaenuddin, D., H. Marwan, H. Subagyo, A. Mulyani, dan N. Suharta. 2000. Kriteria Kesesuaian Lahan untuk Komoditas Pertanian. Departemen Pertanian. 264 hlm.

FAO. 1976. A Framework For Land Evaluation. FAO Soil Bulletin 32. Food and Agriculture Organization of united nations. Rome $87 \mathrm{p}$.

Hardjowigeno, S dan Widiatmaka. 2007. Evaluasi Kesesuaian Lahan dan Perencanaan 
Tataguna Lahan. Bogor: Gadjah Mada University Press. Jakarta.

Huda, K. 2010. Budidaya Tanaman Ubi Kayu (Manihot esculenta crantz). LIPTAN. http:// hudamagazine.blogspot.com/2010/01/budidaya- ubi-kayu-manihot-esculenta.html. Di akses pada tanggal : 19 Agustus 2011.

Ibrahim, Y. 2003. Studi Kelayakan Bisnis. Rhineka Cipta. Jakarta. 249 hlm. 